\title{
Aeruginocine typing of Pseudomonas aeruginosa
}

\author{
SHRINIWAS \\ From the Department of Microbiology, All-India Institute of Medical Sciences, Ansari Nagar, New Delhi, \\ India
}

SYNOPSIS Aeruginocine typing using eight indicator strains of Wahba on Bacto tryptone-glucose yeast extract Agar (Difco) with an incubation temperature of $32^{\circ} \mathrm{C}$ was found to be a reproducible and easy method which could be readily adopted by a diagnostic clinical laboratory. The results of aeruginocine typing of 1500 strains of Ps. aeruginosa suggest that hospitals differ in the range and patterns of aeruginocine types of strains isolated in them. In addition to representatives of nine of the 10 pyocine types of Wahba, a large number of strains isolated in India were found to fall into other groups not described in Wahba's system. Hence, 20 new inhibition patterns (aeruginocine types) are proposed.

An increase in the incidence of infection caused by Pseudomonas aeruginosa has been reported both from India and abroad (Carroll, 1955; Lancet, 1961; Curtin et al, 1961; Gould, 1963; Dube and Shriniwas, 1965; Naidu and Gupta, 1966; Tagg and Mushin, 1971; Heckman, Babcock, and Rose, 1972; Subramanian, Prakash, Shriniwas, and Bhujwala, 1973). That increase has been attributed to the use of broad-spectrum antibiotics, corticosteroids, immunosuppressive and cytotoxic drugs, prolonged surgical procedures, mechanical instrumentation, and an aging population. However, little is known in the majority of instances about the source of the infection and the route of spread. $P s$. aeruginosa is known to be a frequent contaminant of respiratory apparatus, humidifiers, drainage bottles, and other hospital equipment and is highly resistant to many disinfectants and antibiotics (Dube and Shriniwas, 1965; McNamara, Hill, Balows, and Tucker, 1967; Tinne, Gordon, Bain, and Mackey, 1967; Rountree and Beard, 1968). Typing methods have been found useful in tracing the sources and routes of infection with Pseudomonas aeruginosa. Wahba (1963 and 1965) and Darrell and Wahba (1964) used the property of pyocine production for the typing of Ps. pyocyanea. The pyocine typing was done by observing the inhibitory effect of the pyocine produced by the test strains on a set of 12 indicator strains. It was reported by Matsumoto, Tazaki, and Kato (1968) that Wahba had subsequently replaced three of the indicator

Received for publication 23 October 1973. strains (H 1180, H 323, and E 826) by another three (584, 577, and 593). Parker (personal communication) has informed me that the three substituted indicators were not essential in defining the main patterns or 'types' described by Wahba (A, B, C, D $\mathrm{E}$, etc) which are recognized with the remaining nine indicators. The new indicators, on the other hand, are useful for recognizing subdivisions in the original A and B patterns of Wahba (1965).

The International Committee on the Nomenclature of Bacteria, Judicial Commission (1970) has accepted the name Pseudomonas aeruginosa in place of Pseudomonas pyocyanea. It is, therefore, proposed to use the term 'aeruginocine' in place of 'pyocine'.

The purpose of the present paper is to show that, by the use of only eight original indicator strains of Wahba, a method of aeruginocine typing can be established. Some new inhibition patterns (aeruginocine types) and a method of reporting uncommon types have been proposed which could be used for reporting the typing results.

\section{Materials and Methods}

One thousand five hundred strains of Ps. aeruginosa isolated from clinical material from six hospitals in different parts of the country were examined by the aeruginocine typing method.

Ps. aeruginosa was identified according to the scheme of Shriniwas and Bhatia (1969) on the basis of colonial morphology, pigment production, fluorescence, inability to ferment any sugar except 


\begin{tabular}{|c|c|c|c|c|c|c|c|c|c|}
\hline \multirow[t]{3}{*}{ Type } & \multicolumn{8}{|c|}{ Indicator Strains } & \multirow{3}{*}{$\begin{array}{l}\text { No. of } \\
\text { Strains }\end{array}$} \\
\hline & 1 & 2 & 3 & 4 & 5 & 6 & 7 & 8 & \\
\hline & M8 & $B 10$ & $S 17$ & $B 26$ & B39 & $A 52$ & $8 / 39$ & $10 / 55$ & \\
\hline $\mathbf{A}$ & - & + & + & + & + & + & + & + & 122 \\
\hline B & + & + & + & - & + & + & + & - & 18 \\
\hline C & + & - & + & + & + & + & t. & + & 0 \\
\hline D & + & - & + & - & + & - & + & - & 2 \\
\hline $\mathbf{F}$ & + & + & - & - & + & + & + & - & 94 \\
\hline $\mathbf{G}$ & - & + & + & - & - & + & - & - & 16 \\
\hline $\mathbf{K}$ & - & + & - & - & + & - & + & - & 2 \\
\hline $\mathbf{L}$ & - & - & - & - & - & + & - & - & 22 \\
\hline 0 & - & - & - & - & + & - & + & - & 4 \\
\hline $\mathbf{P}$ & + & - & - & - & - & - & - & - & 19 \\
\hline $\begin{array}{l}\text { No inhibition }{ }^{1} \\
\text { Unclassifiable } \\
\text { Total }\end{array}$ & - & - & - & - & - & - & - & - & $\begin{array}{r}247 \\
954 \\
1500\end{array}$ \\
\hline
\end{tabular}

Table I Distribution of 1500 strains of Pseudomonas aeruginosa into Wahba pyocine typing patterns of inhibition

${ }^{1}$ No inhibition of indicator strain

'Unclassifiable strains, ie, strains giving patterns other than those described by Wahba (1965).

$+=$ Inhibition of indicator strain $(2 \mathrm{~cm}$ or more)

$\underline{-}=$ No inhibition of indicator strain

oxidative fermentation of glucose, a positive oxidase test, and growth at $42^{\circ} \mathrm{C}$. The aeruginocine typing was done according to the method of Darrell and Wahba (1964) as modified by Shriniwas, Bhatia, and Ramachandran (1971). Only eight indicator strains were used for aeruginocine typing in the present study (table I). Indicator strain M 283 was regarded as not useful in defining main patterns, as it was negative in all the inhibition patterns of Wahba except in A and B in which it may be positive or negative as is seen in table IV. The indicator as well as the test strains were maintained by repeated subcultures on semi-solid agar in screw-cap bijou bottles (Cruickshank, 1965), and were stored at $4^{\circ} \mathrm{C}$. Indicator strains were also maintained in the lyophilized state. The aeruginocine typing was done by first inoculating the test strains to be typed on nutrient agar plates. After overnight incubation of the plates isolated colonies were picked up and inoculated in nutrient broth, which was incubated at $37^{\circ} \mathrm{C}$ for four hours. The strain was then streaked as a $1 \mathrm{~cm}$ wide band in the middle of Bacto tryptone glucose yeast extract agar (Difco) plates, about $8 \mathrm{~mm}$ deep, prepared according to the instructions of the manufacturer. The inoculated plates were incubated at $32^{\circ} \mathrm{C}$ for about 14 to 16 hours. At the end of the incubation period, the growth was scraped off with a sterile glass slide and any invisible growth left behind was killed by exposing the plate to chloroform vapour for 15 minutes. The four-hour growth of each indicator strain in glucose broth was inoculated by cross streaking. The results were read after incubation overnight at $32^{\circ} \mathrm{C}$. The inhibition patterns of strains producing inhibition of indicator strain/s were noted and those producing no inhibi- tion of any indicator strain were recorded as not typable. All the strains were typed by the above procedure at least three times and only when the same inhibition pattern was produced by a strain on three occasions, was a grouping result recorded.

\section{Results}

The aeruginocine typing of 1500 strains of $P s$. aeruginosa using eight indicator strains of Wahba produced 154 inhibition patterns. Two hundred and forty seven $(16.5 \%$ strains did not produce inhibition of any indicator strain and were grouped as not typable (NT). The inhibition patterns were usually reproducible on repeated typing which was done at least thrice. In a very few instances the inhibition patterns could not be reproduced on a second or a third occasion. On further investigation of all these cultures, similar colonial types of $P S$. aeruginosa which had different reproducible aeruginocine types were found. Thus in all the instances where replicate typing showed more than one aeruginocine type or pattern, the stock culture was found to be mixed, containing the different aeruginocine types. Aeruginocine types remained unchanged after storage of strains for one year under conditions of culture and storage described in this paper.

Only 299 strains $(19 \cdot 2 \%)$ could be grouped into Wahba 'inhibition patterns' or pyocine (aeruginocine) types. Inhibition pattern (pyocine type) $C$ of Wahba was not produced by any strain of the present study. Wahba inhibition patterns (pyocine types) $D, K$, and $O$ were produced by two, two, and four strains respectively, hence these are not common pyocine types encountered in this country. Thus 


\begin{tabular}{|c|c|c|c|c|c|c|c|c|c|}
\hline \multirow{2}{*}{$\begin{array}{l}\text { Aeruginocine } \\
\text { Type }\end{array}$} & \multicolumn{8}{|c|}{ Indicator Strains } & \multirow{2}{*}{$\begin{array}{l}\text { No. of } \\
\text { Strains }\end{array}$} \\
\hline & 1 & 2 & 3 & 4 & 5 & 6 & 7 & 8 & \\
\hline 1 & + & + & + & - & + & + & + & + & 231 \\
\hline 2 & + & + & - & - & + & + & + & + & 43 \\
\hline 3 & + & + & - & + & + & + & - & - & 43 \\
\hline 4 & + & - & - & - & + & - & - & - & 27 \\
\hline 5 & + & - & - & + & + & - & + & - & 16 \\
\hline 6 & + & + & + & - & + & - & - & + & 16 \\
\hline 7 & - & - & - & - & - & - & - & + & 16 \\
\hline 8 & + & - & - & - & - & - & - & - & 17 \\
\hline 9 & + & + & + & - & + & + & - & - & 15 \\
\hline 10 & - & - & - & - & + & + & - & - & 15 \\
\hline 11 & + & + & - & - & + & + & - & - & 17 \\
\hline 12 & + & - & - & - & + & + & - & - & 15 \\
\hline 13 & - & - & - & - & + & + & - & + & 12 \\
\hline 14 & - & + & - & - & - & - & - & - & 21 \\
\hline 15 & + & + & - & + & + & + & + & + & 13 \\
\hline 16 & + & - & - & - & - & + & - & - & 12 \\
\hline 17 & + & + & + & + & + & + & + & - & 17 \\
\hline 18 & - & + & - & - & - & + & - & - & 12 \\
\hline 19 & - & + & - & - & + & + & + & - & 17 \\
\hline 20 & - & - & - & - & + & - & - & - & 12 \\
\hline Total & & & & & & & & & 587 \\
\hline
\end{tabular}

Table II Proposed new inhibition patterns (aeruginocine types) of strains of Pseudomonas aeruginosa unclassifiable into Wahba pyocine typing patterns

$+=$ Inhibition of indicator stıain ( $2 \mathrm{~cm}$ or more)

$-=$ No inhibition of indicator strain

954 typable strains $(63.6 \%)$ could not be grouped into Wahba inhibition patterns and were graded unclassifiable (table I).

On further analysis of the unclassifiable group, it was decided to subdivide this group into two: A Inhibition patterns or aeruginocine types which were found in more than $\mathbf{1 0}$ strains. There were 20 such inhibition patterns and it was proposed to number them from 1 to 20 using Arabic numerals (table II). B Inhibition patterns or aeruginocine types which were found in 10 or fewer strains. There were 125 such inhibition patterns and it was proposed to group them as unclassifiable and report the individual inhibition pattern (table III).

In this way $587(39.1 \%)$ typable strains which did not belong to any of Wahba's types could be allotted to proposed aeruginocine types, each represented by more than 10 strains (table II). Thus the

\begin{tabular}{lcc}
\hline $\begin{array}{l}\text { No. of Strains } \\
\text { in each Pattern }\end{array}$ & $\begin{array}{l}\text { No. of Patterns } \\
\text { Produced }\end{array}$ & $\begin{array}{l}\text { Total No. } \\
\text { of Strains }\end{array}$ \\
\hline 1 & 59 & 59 \\
2 & 17 & 34 \\
3 & 11 & 33 \\
4 & 6 & 24 \\
5 & 8 & 40 \\
6 & 10 & 60 \\
7 & 5 & 35 \\
8 & 2 & 16 \\
9 & 4 & 36 \\
10 & 3 & 30 \\
Total & 125 & 367 \\
\hline
\end{tabular}

Table III Uncommon inhibition patterns of unclassifiable strains total number of typable strains which could not be classified as Wahba's types or the proposed aeruginocine types was reduced to $367(24.5 \%)$ producing 125 inhibition patterns, 59 of which were each produced by one strain only. These inhibition patterns appeared to be uncommon and as such may be? reported as unclassifiable. The largest number of strains in any aeruginocine type was $231(15.4 \%)$ in aeruginocine type no. 1 followed by Wahba pyocine type A with $122(8 \cdot 1 \%)$ strains.

\section{Discussion}

Wahba (1965) proposed 10 inhibition patterns (pyocine types) using 12 indicator strains (table IV). He subsequently replaced three of his original indicator strains $(\mathrm{H} \mathrm{1180}, \mathrm{H} \mathrm{323}$, and $\mathrm{E} \mathrm{826)}$ by three others $(584,577$, and 593) which are useful for recognizing subdivisions in the original inhibition patterns $A$ and $B$ and are not essential in defining the main patterns or 'types' described by him (Parker, personal communication). As is evident from table IV, M 283 also seems to be useful in subdividing patterns $A$ and $B$. It was, therefore, reasonable to decide to use only eight indicator strains and refer to Wahba inhibition patterns on the basis of inhibition of these strains. Wahba could group all his 1899 strains into 10 inhibition patterns and not typable (no inhibition of any indicator strain). However, Matsumoto et al (1968), using Wahba's new set of 12 indicator strains, could not group many of their strains into Wahba inhibition 


\begin{tabular}{|c|c|c|c|c|c|c|c|c|c|c|c|c|}
\hline & 1 & 2 & 3 & 4 & 5 & 6 & 7 & 8 & 9 & 10 & 11 & 12 \\
\hline & M8 & $B 10$ & $S 17$ & $B 26$ & B39 & $A 52$ & $8 / 39$ & $10 / 55$ & $H 1180^{1}$ & $M 283$ & $H 323^{2}$ & $E 826^{2}$ \\
\hline A & + & - & + & + & + & + & + & + & - & $+O R-$ & + & + \\
\hline B & + & + & + & - & + & + & + & - & - & $+O R-$ & + & - \\
\hline C & + & - & + & + & + & + & + & + & - & - & - & + \\
\hline D & + & - & + & - & + & - & + & - & - & - & - & + \\
\hline $\mathbf{F}$ & + & + & - & - & + & + & + & - & - & - & + & + \\
\hline G & - & + & + & - & - & + & - & - & - & - & - & + \\
\hline $\mathbf{K}$ & - & + & - & - & + & - & + & - & - & - & + & - \\
\hline L & - & - & - & - & - & + & - & - & - & - & - & - \\
\hline $\mathbf{O}$ & - & - & - & - & + & - & + & - & - & - & - & $\therefore$ \\
\hline $\mathbf{P}$ & + & - & - & - & - & - & - & - & - & - & - & - \\
\hline NT & - & - & - & - & - & - & - & - & - & - & - & - \\
\hline
\end{tabular}

Table IV Wahba pyocine patterns of inhibition of the 12 indicator strains

$+=$ Inhibition of indicator strain ( $2 \mathrm{~cm}$ or more)

- = No inhibition of indicator strain

${ }^{1}$ Replaced by 584

'Replaced by 577

${ }^{3}$ Replaced by 593

patterns and chose to describe the pyocine types of their strains by showing the number of indicator strains which were inhibited and not according to the pyocine types of Wahba. In a previous study Shriniwas et al (1971) have reported results of pyocine typing of 300 strains of Ps. aeruginosa using Wahba's new set of indicator strains, by indicating the number of indicator strains which were inhibited by the organisms. All the 300 strains were grouped into 30 inhibition patterns and nottypable strains.

While analysing the results of 1500 strains of $P s$. aeruginosa in the present series it was observed that they produced as many as 154 different inhibition patterns, 59 of which were produced each by one strain only. It was felt that reporting the results according to Matsumoto et al is not likely to be useful in the study of this organism for epidemiological purposes, and a system has to be evolved which could be followed at different centres so that the results of different studies can be compared. It was, therefore, decided to report the inhibition patterns first according to Wahba and those which could not be classified by Wahba's system were to be grouped as unclassifiable. The unclassifiable group was further subdivided into two (A) inhibition patterns which were found in more than 10 strains, and (B) inhibition patterns which were found in 10 or fewer strains. In this way 20 new inhibition patterns (aeruginocine types) have been proposed. Only $299(19.9 \%)$ strains could be grouped into Wahba pyocine types; $247(16.5 \%)$ strains did not produce inhibition of any indicator strain and were grouped as not typable and $587(39 \cdot 1 \%)$ could be grouped into the proposed new inhibition patterns (aeruginocine types). Thus a total of $886(59 \cdot 1 \%)$ strains could be grouped according to the proposed scheme, $247(16.5 \%)$ strains were not typable, leaving $367(24.5 \%)$ strains producing 125 inhibition pattern. Table III shows that as many as 59 patterns were produced each by one strain only and 17 and 11 patterns were produced each by two and three strains respectively thus indicating that these strains are not commonly isolated in India. It is proposed to group these uncommon strains as unclassifiable and report their aeruginocine type by indicating the number of the indicator strain/s inhibited as was reported by Matsumoto et al (1968) and Shriniwas et al (1971). It is important to mention here that Wahba pyocine types $\mathrm{D}, \mathrm{K}$, and $\mathrm{O}$ were found in two, two, and four strains respectively but have not been grouped as unclassifiable as they produced a known inhibition pattern; however, these pyocine types are not encountered frequently in India. It is possible that certain aeruginocine types are more prevalent in British hospitals and certain others in Indian hospitals and hospitals of other countries. This is further supported by the finding that 954 $(63.6 \%)$ strains in the present series had clearly defined aeruginocine types other than those reported by Wahba. The commonest aeruginocine type in the present series was no. 1 of the proposed new aeruginocine types having $231(15.4 \%)$ strains followed by Wahba pyocine type A with $122(8 \cdot 1 \%)$ strains. Analysis of the results suggests that, with the exception of pyocine type A of Wahba, hospitals may differ in the pattern of aeruginocine types in their patient population.

Another system of pyocine typing is that of Gillies and Govan (1966) who proposed 36 different pyocine types on the basis of patterns of inhibition of their eight indicator strains. Govan and Gillies 
(1969) have added one more common inhibition pattern, thus making a total of 37 pyocine types. However, they were not able to group all their strains into these 37 pyocine types and have introduced another group, 'unclassifiable', to include solitary strains giving inhibition patterns other than the 37 types proposed. Heckman et al (1972) using the method and indicator strains of Gillies and Govan, could not place $3.8 \%$ of their strains which had clearly defined pyocine types into any of the one to 37 types of Gillies and Govan and have designated them 'V.A.' after the name of their hospital. They have advocated the introduction of new pyocine types for more frequently encountered inhibition patterns.

Thus it is felt that introduction of the new aeruginocine types is reasonable and is likely to be useful in aeruginocine typing of strains of $P$ s. aeruginosa The modified aeruginocine typing method is reproducible and does not require sophisticated equipment or involved procedures like serological or bacteriophage typing. It can, therefore, be easily adopted by a clinical bacteriology laboratory.

I should like to thank Professor L. N. Mohapatra for his keen interest in the work, Mrs Saroj Mohan for careful technical assistance, and Professor T. Bergan, Kaptein W. Wilhelmsen og Frues, Bakteriologiske Institut, Rikshospitalet, University of Oslo, Oslo, Norway, for supplying the Wahba indicator strains. I also wish to record my indebtedness to all those who have supplied the organisms for aeruginocine typing from different parts of the country.

\section{References}

Carroll, G. (1955). The changing flora in urinary infection in this antibiotic age. J. Urol., 73, 609-612.

Cruickshank, R. (1965). Medical Microbiology, 11 th ed., p. 743. Livingstone, Edinburgh and London.
Curtin, J. A., Petersdorf, R. G., and Bennett, I. L. (1961). Pseudomonas bacteremia: review of ninety-one cases. Ann. intern. Med., 54, 1077-1107.

Darrell, J. H., and Wahba, A. H. (1964). Pyocine typing of hospital strains of Pseudomonas pyocyanea. J. clin. Path., 17, 236-242.

Dube, B., and Shriniwas (1965). Pseudomonas pyocyaneus infections in Varanasi. J. Indian med. Ass., 45, 532-536.

Gillies, R. R., and Govan, J. R. W. (1966). Typing of Pseudomonas pyocyanea by pyocine production. J. Path. Bact., 91, 339-345.

Gould, J. C. (1963). Pseudomonas pyocyanea infections in hospital. In Infection in Hospitals: Epidemiology and Control, edited by R. E. O. Williams and R. A. Shooter, pp. 119-130. Blackwell, Oxford.

Govan, J. R. W., and Gillies, R. R. (1969). Further studies in the pyocine typing of Pseudomonas pyocyanea. J. med. Microbiol., 2, 17-25.

Heckman, M. G., Babcock, J. B., and Rose, H. D. (1972). Pyocine typing of Pseudomonas aeruginosa: clinical and epidemiologiral aspect. Amer. J. clin. Path., 57, 35-42.

Internationa! Committee of Nomenclature of Bacteria, Judicial Commission (1970). Designation of strain ATCC 10145 as the neotype strain of Pseudomonas aeruginosa (Schroeter) Migula Inst. J. syst. Bact., 20, 15-16.

Lancet (1961). Leading article. Green for danger. Lancet, 2, 352-353.

McNamara, M. J., Hill, M. C., Balows, A., and Tucker, E. B. (1967) A study of the bacteriologic patterns of hospital infe ctions Ann. intern. Med., 66, 480-488.

Matsumoto, H., Tazaki, T., and Kato, T. (1968). Serological and pyocine types of Pseudomonas aeruginosa from various sources. Jap. J. Microbiol., 12, 111-119.

Naidu, M. Lakshmi, and Gupta, V. V. S. (1966). A study of Pseudomonas pyocyanea infections in hospital patients. Med. \& Surg., 6, 6-13.

Rountree, P. M., and Beard, M. A. (1968). Sources of infection in an intensive care unit. Med. J. Aust., 1, 577-582.

Shriniwas, and Bhatia, V. N. (1969). Identification of Pseudomonas aeruginosa. J. commun. Dis., 1, 274-278.

Shriniwas, Bhatia, V. N., and Ramachandran, K. (1971). Pyocine types and antibiotic sensitivity of hospital strains of Pseudomonas aeruginosa. Indian J. Path. Bact., 14, 24-31.

Subramanian, K. A., Prakash, A., Shriniwas, and Bhujwala, R. A.? (1973). Post-operative wound infection. Indian J. Surg., 35, 57-64.

Tagg, J. R., and Mushin, R. (1971). Epidemiology of Pseudomonas aeruginosa infection in hospitals. I. Pyocine typing of Ps. aeruginosa. Med. J. Aust., 1, 847-852.

Tinne, J. E., Gordon, A. M., Bain, W. H., and Mackey, W. A. (1967). Cross infection by Pseudomonas aeruginosa as a hazard of intensive surgery. Brit. med. J., 4, 313-315.

Wahba, A. H. (1963). The production and inactivation of pyocines. J. Hyg. (Lond.), 61, 431-441.

Wahba, A. H. (1965). Hospital infection with Pseudomonas pyocyanea: an investigation by a combined pyocine and serological typing method. Brit. med. J., 1, 86-89. 